\title{
Highly-controlled synthesis of organic layers on mesoporous silica: their structure and application to toxic ion adsorptions
}

\author{
Hideaki Yoshitake* \\ Graduate School of Environment and Information Sciences,Yokohama National University, 79-7 Tokiwadai, \\ Hodogaya-ku, Yokohama 240-8501, Japan. Fax: +81 (0)45 339 4378; Tel: +81 (0)45 339 4378; E-mail: \\ yos@ynu.ac.jp
}

\section{This submission was created using the RSC Article Template (DO NOT DELETE THIS TEXT) (LINE INCLUDED FOR SPACING ONLY - DO NOT DELETE THIS TEXT)}

\begin{abstract}
Since the discovery of ordered mesoporous silica, control of the structure of organic layers at the mesoscopic level has become a topic of growing interest for the modification of silica surfaces. In addition, the microstructure of functional groups on the surface also produces new problems specific to mesoporous silica. Our interest in this field consists in revealing potential problems in the synthesis of modified mesoporous silica for achieving a uniform structure, developing new synthetic routes to highly-functionalized solids and elucidating the mechanism where they work as an adsorbent. All these objectives will be described both on the mesoscopic and microscopic scales. The comparison of in-advance silane synthesis with post on-surface modification is related mainly to the uniformity in the molecular structure of the functional groups. On the other hand, the differences emerging from the comparison between grafting and direct co-condensation are often attributed to the uniformity in the dispersion of the organic groups. The density of the functional groups, which is often regarded as an important specification of the material, is discussed in detail, especially in terms of the mesoscopic uniformity, the method of dispersion (explored by changing the numbers of the functional groups per organic chain or per unit surface area and by changing the stage of synthesis where the modification is carried out) and the distribution on the solid. A refined direct co-condensation method, functionalization associated with templating, has several advantages in the exposure of all functional groups as well as in selective modification of the internal pore surface. The performance of ion adsorption is discussed in relation to the structural differences caused by the choice of synthetic method, small differences in the adsorption sites and the mesopore framework structures.
\end{abstract}

\section{Introduction}

The modification of amorphous silica surfaces by the attachment of organic functionalities is an important research area for adsorption, catalysis, separation and sensors, and has provided enormous inspiration in the field of organic-inorganic composite materials. The study has been greatly accelerated since the discovery of the micelle-templating method for preparing periodic ordered mesoporous silicas, ${ }^{1,2}$ probably due to the large surface area and well developed pore structure with large defined windows $(>2 \mathrm{~nm})$. The large pore size has revealed potential concerns in many areas because the variation of the molecules accommodated by the pores is considerably more extensive than that in the host-guest chemistry of microporous materials. In addition, a high concentration of surface $\mathrm{Si}-\mathrm{OH}$ groups ${ }^{3-5}$ has often been regarded as a strong point for binding guest molecules and surface modifiers, considering that the pore surface of zeolite is normally hydrophobic. These properties have motivated applications in which environmentally toxic ions are adsorbed by mesoporous silica. The modification with organic chains has become a larger focus of interest in such applications, as the importance of mesoporous silica has become more widely recognized. Several excellent articles reviewing the preparation, characterization and function of these organicinorganic composite systems have been published. ${ }^{6-12}$

We can easily substantiate, from data in the literature, the excellent adsorption performance of mesoporous silica modified with organic functional groups as far as it is measured per unit weight of the solid. Nevertheless, we may be aware that these have sometimes displayed, or presented intentionally, inherent problems related to the structure of the material. These would be static problems, such as the different kinds of "location" in the solid (external surface / internal-pore surfaces, micropores/mesopores, etc.) and inhomogeneous dispersion of organic groups on the surface, as well as synthetic problems such as the attachment of such reactive organic groups, that can destroy the porous structure. The structural uniformity both at the micro and mesoscopic scales can provide higher performance in these applications than have ever been achieved and, therefore, should be searched for. However, the microstructure of mesoporous silica is not as well-defined as that of zeolites and differs even if it is called by the same code name such as MCM41, SBA-15, MSU-X etc. This is part of the nature of ordered mesoporous silicas. Since the micelle-templating method is not only applicable to silica gels but also to various oxide-hydroxide gels, the preparation of the organic layer should be designed as a part of the mesoporous framework formation. In addition, the products should be analyzed as new mesoporous materials because the mesostructure usually differs more from the related pure mesoporous silica than from the other mesoporous silicas labelled with different codes.

The addition of the functional group can be inserted into every step of the basic scheme of mesoporous silica synthesis. As shown in Scheme 1, the silane with a functional organic group can be reacted with mesoporous silica (1), with assynthesized mesoporous silica, i.e. just before the extraction of the template (2), and with the synthetic gel (3). It can also be included as a part of the reactants (4) or as a surfactant micelle (5). Considering that the structure of products varies according to the synthetic method, even when using the same reactants and template, we should design a synthetic route for the organic layer-covered mesoporous silica as well as the molecular structure of organic groups with desired functionalities. It is not possible at the moment, however, to foresee what kind of structural factors in the organic layers can make a significant difference in particular applications such as adsorption and catalysis. Thus a combined study of synthesis via a new route, structural characterization and analysis of the function is considerably valuable in the development of functionalized mesoporous silicas.

In this short review, I raise inherent problems relating to the synthesis of organic layer-modified mesoporous silicas, especially to the achievement of a well defined and uniform structure and to the generation of desired functions. These 
should be discussed in view of the micro- and meso-scopic structures, in order to find clues for determining how these problems appear in toxic ion adsorptions and how they should be conquered. For well defined and uniform organic layers, the structure should be investigated at two levels: the structure of organic groups and the dispersion or location of organic groups. This is discussed in the following two sections. Then, how the difference in these structures is manifested in the adsorption of toxic anions is presented. I briefly discuss the future of the synthesis of organic layers on mesoporous silica in the final section.

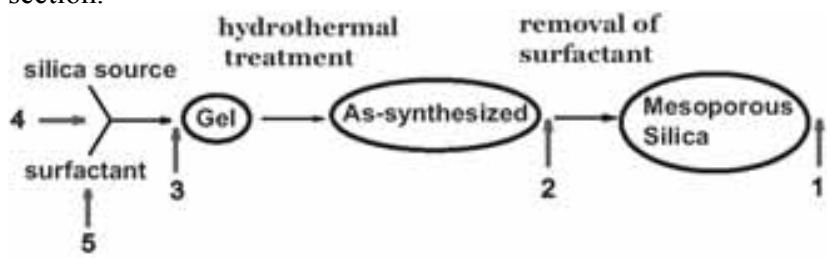

Scheme 1 A basic scheme for the synthesis of mesoporous silica and possible steps where the precursor of functional groups is added. 1: grafting, 2: grafting on "as-synthesized" silica, 3 and 4: direct synthesis and 5: functionalization associated with templating. Although various silica sources can be used in general, TEOS (tetraethyl orthosilicate, $\left.\mathrm{Si}\left(\mathrm{OC}_{2} \mathrm{H}_{5}\right)_{4}\right)$ has been preferred in several kinds of synthesis.

\section{Silane synthesis in advance vs on-surface synthesis (also called post modification): microscopic views of functional groups in advanced synthesis of organic layers}

Grafting is a simple but versatile method for modifying silica surfaces; mesoporous silica is reacted with an appropriate organosilane usually in a solvent. This method has been widely employed since the discovery of ordered mesoporous silica, probably because the large pore $(>2 \mathrm{~nm})$ can accommodate silanes with various molecular sizes. However, the commercial availability of silanes is still limited and a suitable silane has often been synthesized. Typical examples of the silane syntheses published in the literature are the preparation of metal complexes attached to mesoporous silicas such as an Fe(THF) complex, ${ }^{13}$ zirconocene, ${ }^{14}$ rare earth metal complexes, ${ }^{15}$ Schiff base complexes, ${ }^{16}$ a chiral Ti complex for an asymmetric epoxidation site ${ }^{17}$ and a tetraamine $\mathrm{Cu}(\mathrm{II})$ complex. ${ }^{18}$ Organic groupmodified silicas, if they have a complex structure such as a chiral (binaphtyl) group, ${ }^{19}$ have been prepared via this route. The confirmation of the structural identity of functional groups on the surface can be done by a simple comparison of the set of spectroscopic data of the synthesized silane molecule with that of modified silicas. In other words, this synthetic strategy rarely induces an ambiguity in the microstructure unless decomposition of organic groups occurs during silylation. However, this requires a thorough structural analysis of the precursor molecule as in an organic synthesis (elemental analysis, ${ }^{1} \mathrm{H},{ }^{13} \mathrm{C}$ and ${ }^{29} \mathrm{Si}$ $\mathrm{NMR}, \mathrm{IR}$, etc.) and such structural analysis has not always been done.

The on-surface synthesis, where grafted functional groups are converted into a desirable organic group, is sometimes called post modification and has been applied to cases in which the reagent used for the preparation of a desirable functional group can decompose the silane. This method is also suitable for the functional groups that attack the surface of mesoporous silica. After the organic chain is fixed, it does not react freely with the surface due to the restriction of the conformation.

An important application is an acid catalyst preparation. An acidic group in a silane would catalyze the hydrolysis of the silane molecule and, to avoid this reaction, -
$\mathrm{SO}_{3} \mathrm{H}$ should be prepared by oxidation of $-\mathrm{SH}$ (with $\mathrm{H}_{2} \mathrm{O}_{2}$ ) after grafting 3-mercaptopropyltrimethoxysilane (MPTS). ${ }^{20-22}$

The conversion in on-surface reactions is regarded as being less uniform than similar homogeneous reactions so that special attention is necessary in the structural analysis of the solid products. In the oxidation of - $\mathrm{SH}$ of MPTS-grafted mesoporous silica, the conversion into $-\mathrm{SO}_{3} \mathrm{H}$ is relatively easily analyzed by a combination of the elemental analysis of $\mathrm{S}$ and the ion exchange capacity. ${ }^{21}$

A variety of aminoalkyl(trialkoxy)silanes are commercially available and have been widely used for surface modification, while more chain structures have been pursued. The attachment of amines on modified mesoporous silicas, ${ }^{23-29}$ summarized in Scheme 2, has been widely studied. These aminofunctionalized mesoporous silicas have been used for base catalysts and cation traps. One of the barriers to obtaining a uniform microstructure is the multiple substitution of an amine because most of these amines can react with two or more surface organic groups. This reaction can happen in a monoamine as well as in a polyamine. The elemental analysis of the product powder gives only an average composition. In order to determine the structure of organic groups on the surface, an insight into the mesostructure is needed as well as conventional spectrochemical analyses such as IR and ${ }^{13} \mathrm{C}-\mathrm{NMR}$.

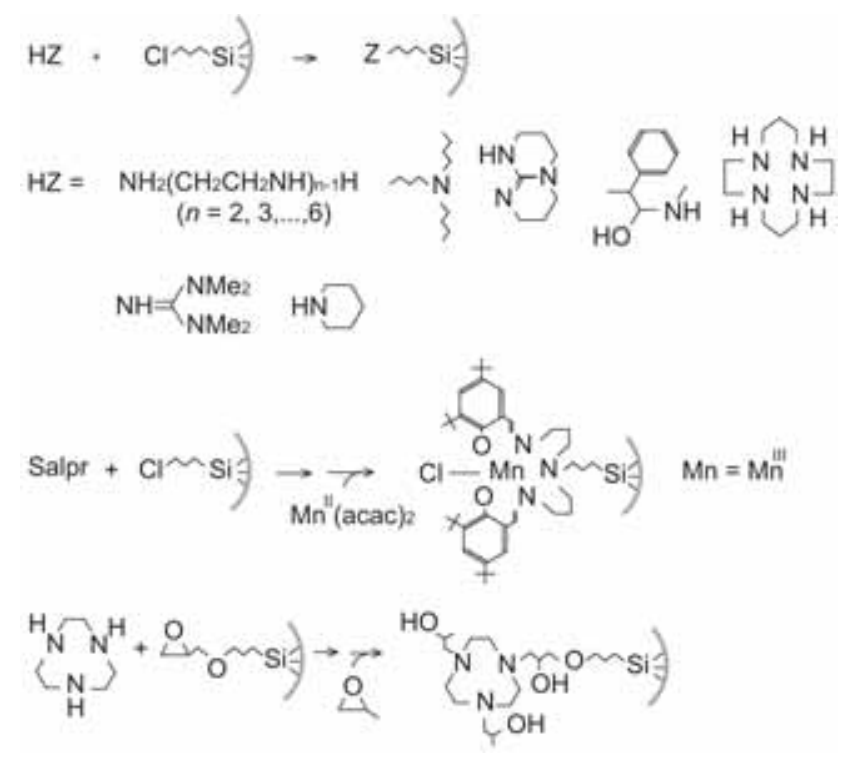

Scheme 2 Amine reaction with surface organic groups on mesoporous silicas.

We have investigated the structure of polyamine chains on MCM-41, which is prepared by the reaction of 3chloropropylsilyl-MCM-41 and linear polyamine molecules $\left(\mathrm{NH}_{2}\left(\mathrm{CH}_{2} \mathrm{CH}_{2} \mathrm{NH}\right)_{\mathrm{n}-1} \mathrm{H}, \quad \mathrm{n}=2, \quad 3 \ldots\right)^{29}$ Even in ethylenediamine (EDA) attached propyl-MCM-41, the elemental analysis revealed that EDA : propyl $=1: 2$. Assuming that the reaction with one EDA and three chloropropyl groups is negligible, two forms of organic chains are possible: $\mathrm{Si}-\left(\mathrm{CH}_{2}\right)_{3}-$ $\mathrm{NHCH}_{2} \mathrm{CH}_{2} \mathrm{NH}-\left(\mathrm{CH}_{2}\right)_{3}$ - $\mathrm{Si}$ and $\mathrm{NH}_{2} \mathrm{CH}_{2} \mathrm{CH}_{2} \mathrm{~N}\left[-\left(\mathrm{CH}_{2}\right)_{3}-\mathrm{Si}\right]_{2}$ as illustrated in Figure 1. The formation of both structures was confirmed by infrared absorption, where the bending modes of the primary and secondary amines were observed. ${ }^{13} \mathrm{C}$-MAS NMR is consistent with the coexistence of two structures. Considering that both kinds of bridge structure between two propyl groups are detected, we cannot exclude the possibility of the formation of four or six kinds of surface structure in the reaction of diethylenetriamine (DETA) or triethylenetetramine (TETA), respectively. The formation of such a complicated and ill-defined structure can be avoided when tertiary amine is used, 
which is often inferior to the primary and secondary amines used in the coordination of transition metal ions.

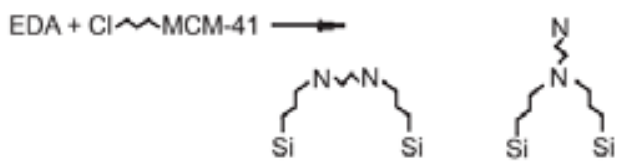

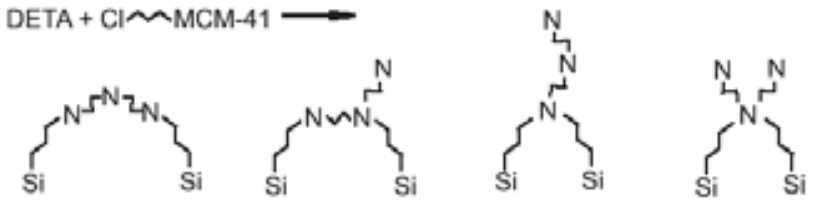

$\mathrm{TETA}+\mathrm{Cl} \sim \mathrm{MCM}-41 \longrightarrow$<smiles>CCNNNNNC[SiH3]</smiles><smiles>NN(CC[Si])NNNCC[Si]</smiles><smiles>N=NN(N)CCS</smiles><smiles>NNNN(C[Si])CC[Si]</smiles>

Figure 1 Possible structures of functional groups prepared by the reaction of 3-chloropropylsilylated MCM-41 with linear polyamines, EDA, DETA and TETA.

Other versatile post modifications include the Heck reaction to add the various aryl groups to the surface ${ }^{30}$ and the Grignard reaction. ${ }^{31}$ Ding et al. reported the conversion of terminal alcoholic $\mathrm{OH}$ on a mesoporous silica $\left(2 R_{\mathrm{p}}=10 \mathrm{~nm}\right.$, not in a periodic structure) surface into a variety of organic groups. ${ }^{32}$ They carried out an elemental analysis to evaluate the degree of transformation and hence the level of new substituent derivatization, which are summarized in Figure 2. All surface compounds showed clear resonances in the ${ }^{13} \mathrm{C}-\mathrm{NMR}$ spectra, accompanied by peaks due to unreacted $\mathrm{HOCH}_{2} \mathrm{CH}_{2} \mathrm{CH}_{2}$ - chains. Their observations demonstrated that none of the reactions they examined, i.e. bromination, esterifications, etherifications, cyanation and Grignard coupling, fully converted the alcoholic $\mathrm{OH}$ and mixed organic layers were always obtained. All of these studies imply that the selectivity and conversion in substitution and addition reactions are usually lower than those in simple oxidation. The structural analysis is usually more complicated than that of free organic molecules unlike the grafting of a silane synthesized in advance.

Péteilh et al. fixed ibuprofen on 3glycidoxypropylsilylated MCM-41 (gly-MCM-41) by an epoxide ring opening reaction in triethylamine and examined the chemical composition of the solid product by thermogravimetry and elemental analysis. ${ }^{33}$ They concluded that $49 \%$ of epoxy groups anchored ibuprofen molecules. On the other hand, with gly-aerosol, which was prepared by grafting 3glycidoxypropylsilane on aerosol \#200, $72 \%$ of epoxy groups were converted into the ibuprofen-attached ester. Although the pore size of the MCM-41 they used was about $10 \mathrm{~nm}$, only low a conversion efficiency was obtained.

The trapping of transition metal cations by modified mesoporous silicas may be classified in the same category. The majority of the studies have been carried out for aminofunctionalized silicas. ${ }^{23,34-39}$ Ligand exchange has become one of the general methods for fixing metals on the surface. ${ }^{41-44}$ Although the coordination environment can be investigated by spectroscopic methods such as UV-vis, ${ }^{35} \mathrm{ESR}^{37,43}$ and EXAFS, 38,45 many of these works have not shown spectroscopic data but only provided the uptake of the metal. It is possible to regard the trapping of cations as adsorption of the cations for which the uptake will be an important characteristic. In regarding this process as part of the synthesis of functionalized mesoporous silica, structural analysis is likely to be required for organomodified mesoporous silica prepared by on-surface synthesis.

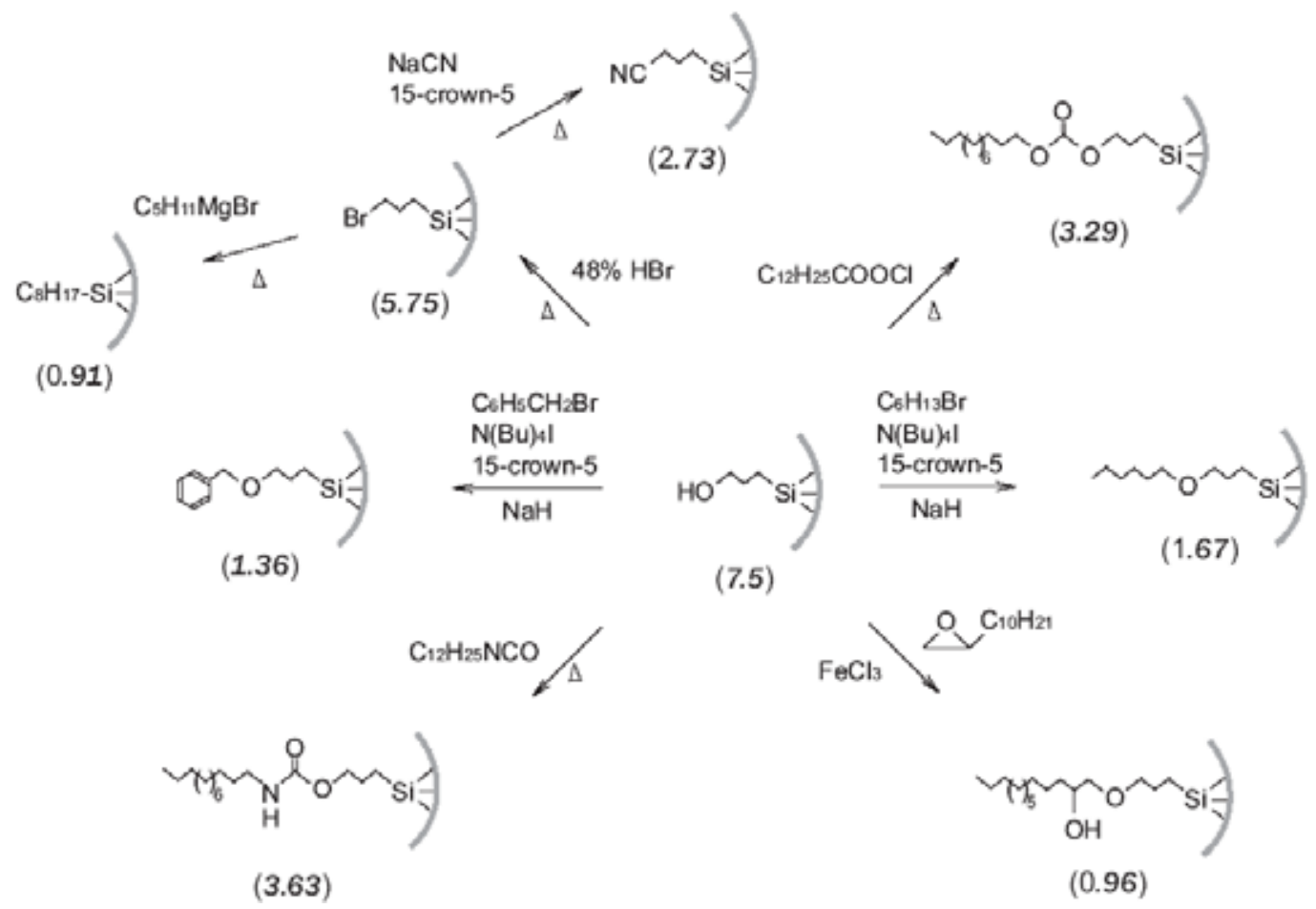

Figure 2 Transformation of propyl-3-ol group on silica. The italicized numbers in parentheses are the surface concentrations of the organic groups in $\mu \mathrm{mol} \mathrm{m} \mathrm{m}^{-2}$. 


\section{Comparison of grafting with direct synthesis (also called one-pot synthesis or co-condensation): mesoscopic view of organic layers}

\section{Dispersion of organic groups in grafted mesoporous silica}

Although the grafting method has been considerably developed, it is widely accepted that a uniform dispersion of organic groups is not often achieved. Ordered mesoporous silica provides three different sites for the reaction: the internal pore surface, the surface near the pore window and the external particle surface. Simple grafting leads to the condensation of organic groups near the pore windows causing "pore blocking," which occurs more readily in silica with small pores than in those with large pores. This structural aspect is critical when we apply grafted mesoporous silica to the adsorption of pollutants.

Our research group has reported the adsorption of aqueous $\mathrm{Co}^{2+}$ ions on 3-aminopropyltrimethoxysilane (APTMS), $\mathbf{H}_{2} \mathrm{NCH}_{2} \mathrm{CH}_{2} \mathrm{CH}_{2} \mathrm{Si}\left(\mathrm{OCH}_{3}\right)_{3}$, aminopropyl]trimethoxysilane,

[1-(2-aminoethyl)-3$\mathbf{H}_{2} \mathbf{N C H}_{2} \mathrm{CH}_{2} \mathbf{H N C H} \mathrm{CH}_{2} \mathrm{CH}_{2} \mathrm{Si}\left(\mathrm{OCH}_{3}\right)_{3}$, and 1-[3(trimethoxysilyl)-propyl]diethylenetriamine,

$\mathbf{H}_{2} \mathrm{NCH}_{2} \mathrm{CH}_{2} \mathbf{H N C H} \mathrm{CH}_{2} \mathbf{H N C H} \mathrm{CH}_{2} \mathrm{CH}_{2} \mathrm{Si}\left(\mathrm{OCH}_{3}\right)_{3}$, grafted MCM-41 $\left(2 R_{\mathrm{p}}=3.6 \mathrm{~nm}\right)$ with various densities of amino groups controlled by changing the silane concentration in toluene at reflux. ${ }^{46}$ The amount of adsorption was not proportional to the amino group density as shown in Figure 3, where the adsorption deviated considerably from a linear function when long organic chains were applied. The nonlinearity can be explained by the following mechanism. A large silane molecule can suffer from inhibition during diffusion into the pores, while the reactivity of methoxy groups is almost the same, and, consequently, it may tend to settle near the pore window where it can inactivate the amino groups by the "congestion" of organic chains as well as interfering with the diffusion of $\mathrm{Co}^{2+}$. On the other hand, all the adsorption data for the functionalized MCM-41 prepared by direct synthesis (see below) with these silanes and TEOS appeared almost on the same line, implying a homogeneous distribution of amino groups in the pores, regardless of the surface density of the organic groups and the structure of the organic chains.
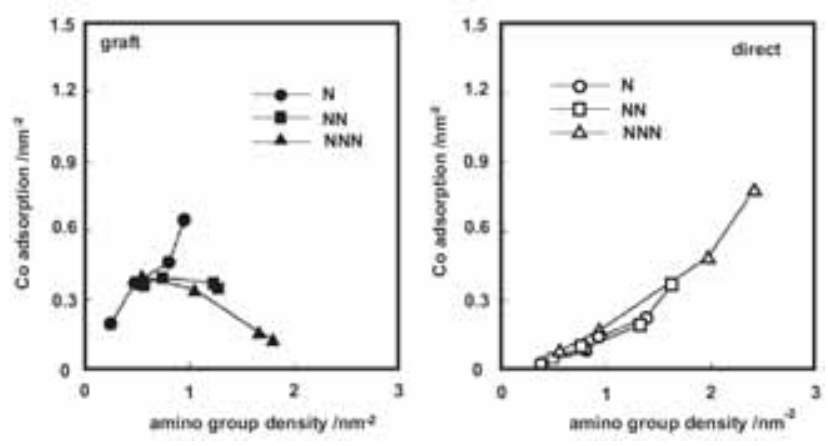

Figure 3 Adsorption of $\mathrm{Co}^{2+}$ on 3-aminopropyltrimethoxysilane, [1-(2aminoethyl)-3-aminopropyl]trimethoxysilane and 1-[3-(trimethoxysilyl)propyl]diethylenetriamine grafted MCM-41, which are denoted by N-, NN- and NNN-MCM-41, respectively, and that on a corresponding organic MCM-41 prepared by direct co-condensation.

Walcarius et al. investigated the kinetics of diffusion during which the reactants were captured by the organic groups grafted on mesoporous silica. The reactions were protonation of aminopropyl-grafted silica (APS-silica), $\mathrm{Hg}^{2+}$ binding on mercaptopropyl-grafted silica (MPS-silica) and accumulation of $\mathrm{Cu}^{2+}$ on APS-silica, with various grafted solids, pore diameters ranging from 4 to $15 \mathrm{~nm}$ and organic group contents of $1.4-1.9$ mmol g ${ }^{-1}$. ${ }^{47,48}$ The diffusion process was $10^{3}-10^{4}$ times slower than that in a homogeneous solution and a simplified model, by which the apparent diffusion coefficient was evaluated, allowed them to show a significant decrease in the access rates upon gradual completion of the reaction. The decrease implies that the reactant concentration in the vicinity of grafted groups is raised progressively and there would less room available to the probe to rapidly reach the remaining active sites. Most of the active organic groups may be located in the pore, considering their findings that the diffusion was faster in solids with larger pore sizes. In the comparison between MCM-silicas (MCM-41 and MCM-48, $\left.2 R_{\mathrm{p}}=3.4-3.8 \mathrm{~nm}\right)$ and amorphous silica $\left(2 R_{\mathrm{p}}=6-7\right.$ $\mathrm{nm})$ with similar porosities, they did not find a significant difference in the performance unless the pore blocking occurred during grafting on the MCM-silica. On the other hand, Bibby and Lemercier have examined the kinetics of $\mathrm{Hg}^{2+}$ adsorption on 3-mercaptopropyltrimethoxysilyl-mesoporous silica prepared by direct synthesis $\left(2 R_{\mathrm{p}}=2.4-2.9 \mathrm{~nm}\right)$. They found that the diffusion coefficient of mercury (II) ion increases as a function of time. The synergistic acceleration of adsorption was suggested. ${ }^{49}$

Since the dispersion of organic groups grafted on mesoporous silica is not often uniform, the apparent density averaged over the solid does not reflect the average distance (and the "real" density) between organic groups in their domains. This inability to predict will become an explicit problem in reactions promoted by the cooperation of two (or more) vicinal functional groups on the surface. The coordination of transition metal cations on amino-functionalized mesoporous silica ${ }^{23,34-39}$, 50,51 is a typical example of this problem. The coordination structure can be different between two surfaces with the same density of amino groups.

The distance between organic chains can be assessed by probe reactions. Yoshitake et al. have shown that an EDA molecule reacts with one $\mathrm{Cl}$ on 3-chloropropylsilyl-SBA-15 (ClPr-SBA-15), while two chlorine atoms are substituted by the formation of an EDA bridge on 3-chloropropylsilyl-MCM-41 (CIPr-MCM-41) as discussed in the previous section. ${ }^{29}$ Both ClPr-modified silicas are prepared by grafting of APTMS. After the grafting, the apparent densities of the CIPr groups are almost the same $\left(1.5 \mathrm{mmol} \mathrm{g}^{-1}\right)$ and the surface areas, 880 and $640 \mathrm{~m}^{2} \mathrm{~g}^{-}$ ${ }^{1}$ for CIPrMCM-41 and CIPr-SBA-15, respectively, allow us to calculate the "apparent" average density of chloropropyl groups: 1.0 and 1.4 ClPr- per $\mathrm{nm}^{2}$ for CIPrMCM-41 and CIPr-SBA-15, respectively. These two kinds of data on the organic groups is indicative that the real distance between CIPr groups is smaller in ClPr-MCM-41 than in ClPr-SBA-15, though the calculated average density per $\mathrm{nm}^{2}$ is lower in ClPr-MCM-41 than in ClPrSBA-15, implying that $\mathrm{ClPr}$ groups are more dispersed on SBA15. This apparent disagreement probably arises because of the difference in pore size: 2.9 and $8.2 \mathrm{~nm}$ for original MCM-41 and SBA-15, respectively. The condensation of silanes can easily occur at the pore windows when the pore size is small. For the reaction of DETA with CIPr-SBA-15, the formation of liner, bridged and branched structures was suggested by elemental analysis and IR spectroscopy. The variation in the surface structures is summarized in Figure 4.

A silane with a bulky organic group can be used for controlling the distance between the functional groups. McKittrick and Jones proposed a "patterning and capping" method. $^{52}$ [3-(trimethoxysilanyl)propyl]-(3,3,3triphenylpropylidene)amine,

$\mathrm{Ph}_{3} \mathrm{CCH}_{2} \mathrm{CH}=\mathrm{NCH}_{2} \mathrm{CH}_{2} \mathrm{CH}_{2} \mathrm{Si}(\mathrm{OMe})_{3}$, was grafted on SBA-15 followed by capping the remaining surface $\mathrm{Si}-\mathrm{OH}$ by hexamethyldisilazane. The resulting solid was hydrolyzed to convert the large 3,3,3-triphenylpropylideneamine group into a small $\mathrm{NH}_{2}$ - group. The amount of the amino group was 0.39 $\mathrm{mmol} \mathrm{g}^{-1}$ (before the capping.) Finally the capping reaction was repeated to avoid the coordination of $\mathrm{NH}_{2}$ - with surface $\mathrm{OH}$. The 
surface aminopropyl groups were well isolated and free. The distance was compared with that on APTMS grafted SBA-15 $\left(1.15 \mathrm{mmol} \mathrm{g}^{-1}\right)$ by the reaction with terephthaloyl chloride, $p$ $\mathrm{ClC}(\mathrm{O}) \mathrm{C}_{6} \mathrm{H}_{5} \mathrm{C}(\mathrm{O}) \mathrm{Cl}$. The organic groups were bridged on the APTMS-SBA-15 while a linear chain was obtained on the "patterned and capped" SBA-15.
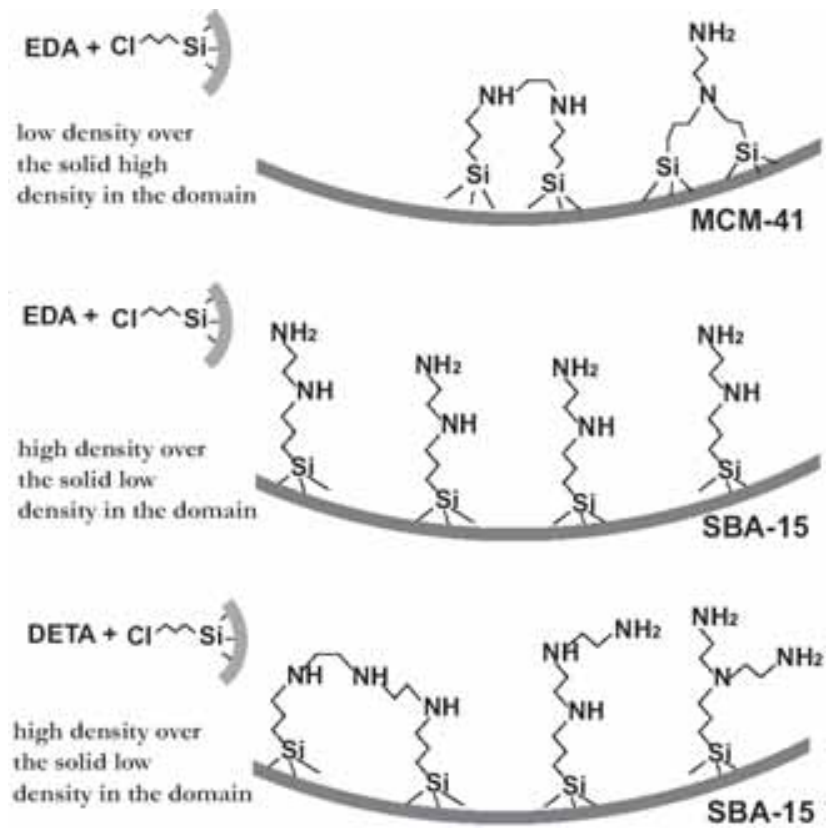

Figure 4 Reaction of EDA and DETA with chloropropyl-functionalized mesoporous silicas.

In a study on vinylsilane-grafted MCM- $41,{ }^{53}$ Lim and Stein showed kinetic data of bromination. Coupled with nitrogen adsorption data, their experiment supported the model in which most of the vinyl groups are located on the external surface and internal surfaces close to the pore windows.

Although the uniform distribution of functional groups in the pores is hardly expected, grafting on mesoporous silica easily enhances the real density of organic groups to higher than expected from the apparent density averaged over the solid. When a manganese in salpr complex was reacted on CIPr-MCM41 (by grafting), the coordination number of $\mathrm{Mn}-\mathrm{O}$ calculated from the $\mathrm{Mn} \mathrm{K}$ edge EXAFS spectrum suggested a pair formation of two Mn complexes. ${ }^{54}$ This result does not seem to be independent of the enhancement of the density of silane.

Grafting is also possible on "as-synthesized" powder, which contains the surfactant inside the mesopores, ${ }^{54,55}$ as illustrated in Scheme 3. The following procedure was employed by Antochshuk and Jaroniec. 54 Silane (3aminopropyltrichlorosilane, n-octyltriethoxysilane, noctyldimethlchlorosilane or 3-mercaptopropylmethoxysilane (MPTMS)) was added to uncalcined mesoporous silica and the mixture was refluxed (without solvent.) The resulting solid was filtered out, washed with benzene and 2-propanol and dried under vacuum at $363 \mathrm{~K}$. The structure of the resulting powder was analysed by elemental analysis, TGA, nitrogen adsorption and XRD. The template was replaced by silanes at $1.25-2.45$ mmol g${ }^{-1}$, with $6 \%$ of template remaining unreplaced. The pore size and BET specific surface area slightly decreased from those $\left(4.9 \mathrm{~nm}\right.$ and $800 \mathrm{~m}^{2} \mathrm{~g}^{-1}$, respectively) of proper calcined MCM41. The $p 6 \mathrm{~mm}$ structure was well retained after the replacement. They noted the advantages of this template displacement by organosilanes as being the efficient removal of the template, elimination of the calcination/extraction steps and, hence, relatively short reaction time. The cationic surfactant for MCM41 synthesis can also be exchanged by cationized aminoalkylsilanes. In this regard, grafting in as-synthesized materials would have similarities with direct template exchange reactions using transition metal complexes. ${ }^{5,57}$ Abry et al. have shown that the distance of chloropropyl groups can be controlled by successive graftings of two kinds of silanes on as-synthesized mesoporous silica. ${ }^{58}$ According to their calculation, the monolayer of orgnic groups covers the silica surface. These studies have demonstrated the high mobility of surfactant in the mesopores and, consequently, whether a uniform dispersion can be obtained or not will depend on the inherent pore size.
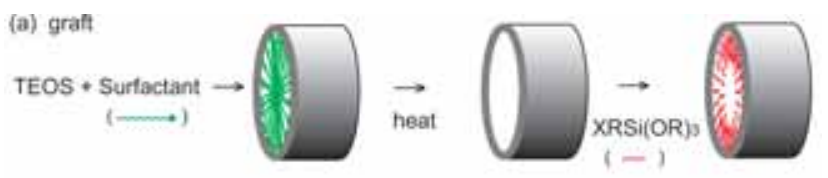

(b) gratt on "as-synthesized"
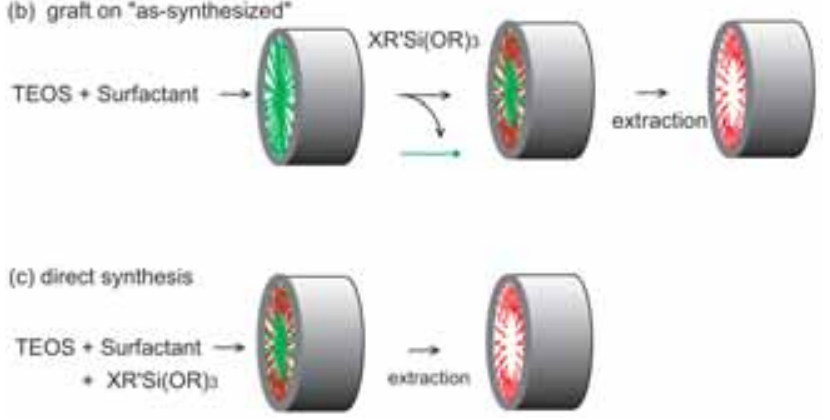

Scheme 3 Illustration of change in the mesopore via grafting of calcined (a) and as-synthesized (b) mesoporous silica. The direct co-condensation (c) is also illustrated.

Apart from narrowing down the pore size, enhancing the surface density of the -OH group is an effective way to augment the "actual" density of functional groups. Coating is a variant method of grafting innovated for this purpose. In the grafting processes silylation reagents are added to the surface where isolated $\mathrm{Si}-\mathrm{OH}$ is expected. On the other hand, a milder drying condition applied to silica results in the formation of a water monolayer on the surface, on which more organosilanes may be attached, leading to a higher concentration of functional groups. ${ }^{59}$ Attention should be paid to prevent water desorption during silylation, which can promote heterogeneous dispersion of organic groups.

\section{Mesoscopic uniformity of direct synthesis (also called co- condensation or one-pot synthesis)}

The co-condensation of organoalkoxysilane, $\mathrm{XR}^{\prime}-\mathrm{Si}(\mathrm{OR})_{3}$, and a silica source with a surfactant micelle is an alternative and widely-employed method to produce a functionalized mesoporous silica. TEOS, $\mathrm{Si}\left(\mathrm{OC}_{2} \mathrm{H}_{5}\right)_{4}$, has been frequetly used for the silica source, probably because the similarity in the condensation process of $-\mathrm{Si}(\mathrm{OR})_{\mathrm{n}}$ is favoured. It should be noted that the number of processes in the preparation is reduced. The early work under this synthetic strategy, which is also called direct or one-pot synthesis, was dedicated to the incorporation of phenyl- and n-octyl functionalities into MCM-41-type materials ${ }^{60}$ and 3-aminopropyl- and 2-cyanoethyl- into a HMS-type silica. ${ }^{61}$ Since then a variety of silanes has been adopted to prepare functionalized silica with MCM-41-, ${ }^{62-67}$ SBA-1-, ${ }^{68}$ HMS-,${ }^{67-70}$ MSU-, ${ }^{71-73}$ SBA-15-motifs ${ }^{74-79}$ via co-condensation. It is generally believed that organic functional groups are, in principle, homogeneously dispersed in mesoporous silica prepared by direct synthesis. However, the post grafting method tends to form much more thermally stable silica networks and often provides higher periodic order than co-condensation. 
Degradation of the periodic order in direct synthesis depends on the kind of functional group. Zhao et al. examined the mesostructural periodicity of functionalized mesoporous silica (with an SBA-15 motif) by co-condensation of TEOS and an organosilane such as 3-aminopropyltriethoxysilane(APTES), 3-mercaptopropylmethoxysilane (MPTMS), phenyltrimethoxysilane (PTMS), vinyltriethoxysilane (VTES) or 4-(triethoxysilyl)bytyronitrile (TSBN) in the presence of the triblock copolymer Pluronic P123. ${ }^{79}$ The levels of disorder were dependent on the type and the amount of organosilane and the disruptive effects followed VTES $<$ TSBN $<$ PTMS $\approx$ MPTMS $<$ APTES. This was attributed to their different beheviour under synthetic conditions and different steric molecular sizes and shapes, which have a direct impact on the interactions of P123 with silicate species and on the micellation of the P123 template. Although the condensation level of the silica framework was different among these silanes, which was shown in the ${ }^{29} \mathrm{Si}$ MAS-NMR spectra, there was little relationship with the above disruptive effects.

It should be pointed out that, in the co-condensation method, the functional groups can be located on the internal pore surface, on the external particle surface and within the framework walls. Even if there is no decomposition of the organic groups during co-condensation, a strong coordination to the silica surface, an attachment in a small pore or an occlusion in the silica framework can deactivate the functional group. Stein et al prepared MCM-41 designated silica by co-condensation of VTES and TEOS. They examined the rate of bromination with various solvents and the profile of brominated vinyl MCM-41 by small angle neutron scattering using a contrast matching technique. They concluded that most of the vinyl groups are accessible to bromine even when the loading was $4.0 \mathrm{mmol} \mathrm{g}$. The bromination rate increased with the pore size. ${ }^{80,81}$ The complete bromination of $\mathrm{C}=\mathrm{C}$ double bonds has also been reported on MCM-41 type silica prepared by one-pot synthesis with an MPTMS/TEOS mixture. ${ }^{82}$

On the other hand, the aminopropyl-functionalized MCM-41 prepared by one-pot synthesis provides inaccessible amino groups. ${ }^{46,83}$ The amount of nitrogen was quantified by argentometric titration and conventional $\mathrm{CHN}$ elemental analysis, indicating that $19 \%$ of amine-nitrogen was inactive to ionexchange when the loading of the amino-group was $1.7 \mathrm{mmol} \mathrm{g}^{-1}$. This is well beyond the systematic errors. According to ref. 76, the disruptive effect of VTES on the mesostructure is the smallest, which allows higher loading of the organic groups, and it has been demonstrated that most of all of the VTES is exposed. ${ }^{80}, \quad 81$ In contrast, the disruptive effect of aminopropylsilane is the largest and a considerable amount of the organic groups was "buried" in the resulting solid. ${ }^{46,83}$ These findings do not seem coincidental but it is likely that a weak or repulsive interaction between the hydrolyzed TEOS and the functional group will lead to the formation of a well defined mesostructure with exposure of the functional groups.

In order to ensure exposure of the organic functional groups in direct synthesis, two methods have been developed separately, ${ }^{83,84}$ in which the functional groups are included in the micelle during hydrolysis of silanes while alkoxy groups in the silane are hydrolyzed with TEOS. We call these methods functionalization associated with templating (FAT). By this method, since the mesoporous framework is built around the micelles, the precursor of the functional group is unlikely to be occluded in the silica matrix and the extraction of the surfactant provides organic groups fully exposed on the surface. In addition, considering that the pore wall is an inverse replica of the micelle surface, it is clear that these organic groups are dispersed only on the internal pore wall surface.

One of the methods is considered to be a variant of direct synthesis for preparing aminopropyl-functionalized mesoporous silica. ${ }^{83}$ To avoid the strong interaction between the amino groups and TEOS-hydrolyzed products, amino groups are bound with terminal groups of carboxylic acid or sulfonic acid surfactants during the micelle formation (Scheme 4). These anionic surfactants cannot, to the best of my knowledge, direct the hydrolysis forming silica with an ordered mesoporous framework and this fact ensures the homogeneous dispersion of organic groups on the mesopore-surface when the porous structure is obtained. When TEOS was co-condensed with 3aminopropyltriethoxysilane (APTES) using lauric acid as a template, an organosilica composite in the mesoporous structure with a wormhole like motif was obtained. The extraction of the surfactant intensified the XRD peaks. The BET surface area was $600 \mathrm{~m}^{2} \mathrm{~g}^{-1}$ and the maximum in the BJH pore diameter distributions was $3.8 \mathrm{~nm}$. The amount of aminopropyl groups, which was measured by ${ }^{29} \mathrm{Si}-\mathrm{NMR}$, reached (aminopropyl$\mathrm{Si}) /($ total $\mathrm{Si})=0.44\left(\mathrm{NH}_{2}\right.$-group: $5.4 \mathrm{mmol} \mathrm{g}$-solid $\left.^{-1}\right)$ as shown in Figure 5 . This is an extremely large density of amino groups. In the conventional co-condensation method using CTMABr surfactant for preparing MCM-41-motif organosilica by applying the same APTES/TEOS ratio in the gel, (aminopropyl-Si)/(total $\mathrm{Si}$ ) reached 0.27 . We confirmed by argentometric titration that $95 \%$ of the amino groups were exposed to the surface, which is unlikely to be due to the direct synthesis of aminopropyl-MCM41 (exposure of amino group: $81 \%$ ). The disagreement of $5 \%$ was attributed to systematic errors as this ratio is constant for all (aminopropyl-Si)/(total $\mathrm{Si}$ ) ratios by this synthetic strategy.

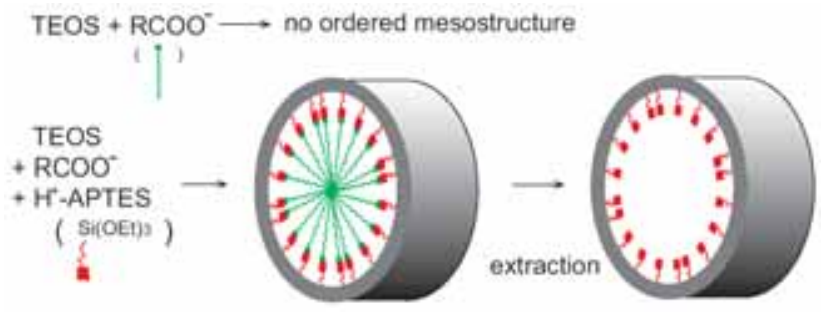

Scheme 4 Functionalization associated with templating: synthesis of aminopropyl-functionalized mesoporous silica by templating assisted by anionic surfactant-amino group interaction.

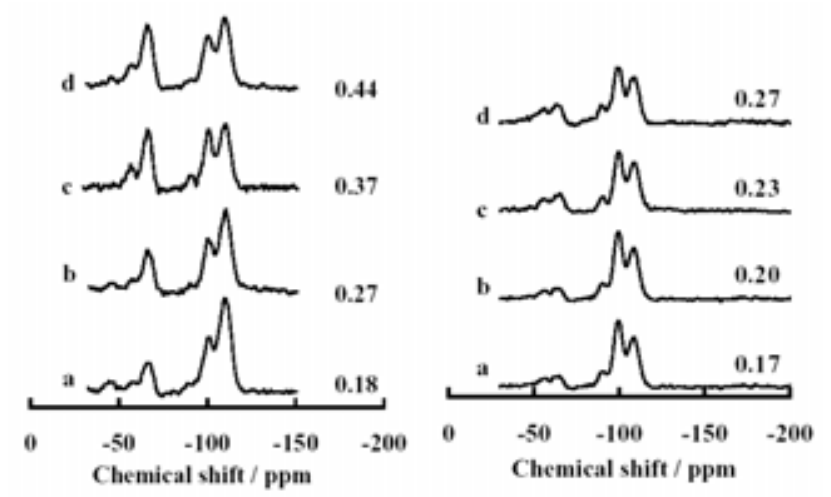

Figure $5{ }^{29} \mathrm{Si}-\mathrm{NMR}$ of mesoporous silica by the FAT method in scheme 4 (APTES-TEOS with Lauric acid, left) and conventional direct synthesis (APTES-TEOS with CTMABr, right). APTES $(x)$ and TEOS $(1-x)$ were mixed with ratios (a) $x=0.2$, (b) $x=0.3$, (c) $x=0.4$ and (d) $x$ $=0.5$. The number accompanying each is $\Sigma T^{\mathrm{n}} /\left(\Sigma T^{\mathrm{n}}+\Sigma Q^{\mathrm{n}}\right)$, which is the fraction of silicon in the aminopropyl group.

The idea of the above ionic interaction-assisted micelle formation came from the framework phase transition of SBA-1 induced by the interaction between embedded-heteropoly acids and cetyltriethoxyammonium cations $\left(\mathrm{CTEA}^{+}\right) .{ }^{85}$ The treatment of as-synthesized heteropoly molybdosilicate-SBA-1 with octanol/water leads the Pm3n structure to a lamellar phase, where most of the surfactants are substituted by octanol but the remaining $\mathrm{CTEA}^{+}$compensates the negative charge of 
heteropoly acid. Without heteropoly molybdosilicate, no transformation occurred after the treatment of as-synthesized SBA-1 with octanol/water. The $\mathrm{CTEA}^{+}$was removable from the heteropoly acid sites to provide a silica sheets-supported heteropoly acid catalyst.

Recently the interaction between the template and the functional group in the silane was conceptually denoted. ${ }^{86}$ Using a cationic surfactant, the functional group will compete with silica oxide-hydroxides in interacting with the surfactant.

An alternative synthetic route proposed by Aruga et al. was named the "lizard template" method. ${ }^{84}$ They synthesized an amphiphilic triethoxysilane with a long organic chain, $\left(\mathrm{C}_{2} \mathrm{H}_{5} \mathrm{O}\right)_{2} \mathrm{Si}\left(\mathrm{CH}_{3}\right) \mathrm{CH}_{2} \mathrm{CH}_{2} \mathrm{CH}_{2} \mathrm{~N}^{+}\left(\mathrm{CH}_{3}\right)_{2} \mathrm{CH}_{2} \mathrm{CONHCH}\left(\mathrm{CH}_{3}\right) \mathrm{CO}$ $\mathrm{OC}_{16} \mathrm{H}_{33} \cdot \mathrm{Br}^{-}$, that could easily be cleaved by acid treatment. This diethoxysilane was condensed with TEOS in an acidic condition and finally the center of the micelle was cut off by treatment with a $\mathrm{THF} / \mathrm{HCl}$ solution to produce an alanine- $\mathrm{COOH}\left(\mathrm{Br}^{-}\right.$. $\left.\mathrm{HOCOCH}\left(\mathrm{CH}_{3}\right) \mathrm{NHC}(\mathrm{O}) \mathrm{CH}_{2} \mathrm{~N}^{+}\left(\mathrm{CH}_{3}\right)_{2} \mathrm{CH}_{2} \mathrm{CH}_{2} \mathrm{CH}_{2}-\right)$

functionalized-mesoporous silica. The authors stated that the idea of this lizard template was inspired by previous work on 2dimensional mesostructured systems ${ }^{87-92}$ and a mesoporous silica. $^{93,94}$ The content of the organic chain was (organo$\mathrm{Si}) /($ total Si $)=0.13\left(\right.$ or $\left.1.2 \mathrm{mmol} \mathrm{g}^{-1}\right)$. The BET surface area was $536 \mathrm{~m} \mathrm{~g}^{2} \mathrm{~g}^{-1}$ with the BJH pore size equal to $2.0 \mathrm{~nm}$, while, after the solid was calcined, it increased to $1301 \mathrm{~m}^{2} \mathrm{~g}^{-1}$. Although assynthesized material showed very weak (110) and (200) reflections in the XRD chart, which suggests a p6mm structure, the peaks with these higher indices disappeared after removal of the template.

It is true that the FAT methods can provide limited kinds of functional groups: amine and alanine- $\mathrm{COOH}$ groups. However, this highly-refined direct synthesis seems to solve most of the critical problems and is suitable for achieving a high density of functional group, all of which are exposed to the pore wall surface. Even though the type of functional groups is quite limited in the FAT methods, they can be converted into desirable organic groups by post on-surface synthesis. In this sense, the FAT method is waiting for new applications such as utilization of a chiral template. ${ }^{95}$

\section{Multiple Functionalization of Specific sites of mesoporous silica}

It is not surprising that the external surface of the silica particles is intended to be modified selectively by organic material while the pore wall surface remains intact and vice versa. The difference between them is more obvious than that found between the sites inside the pores and those near the pore windows. A reactive silane with bulky organic groups such as $\left(\mathrm{C}_{6} \mathrm{H}_{6}\right)_{2} \mathrm{SiCl}_{2}$ was first grafted on calcined MCM-41 (pore diameter: ca. $3 \mathrm{~nm}$ ). ${ }^{96,97}$ In this reaction, most of the kinetically available $\mathrm{Si}-\mathrm{OH}$ was that on the outside surface of silica particles and, hence, these would be deactivated to further reaction. The sample was then treated with APTMS to provide an anchor for a $\mathrm{Ru}$ cluster ${ }^{96}$ or a ferrocenyl compound. ${ }^{97}$ The TEM result led to the conclusion that the amine tethers were present predominantly in the mesopores of MCM-41. ${ }^{96}$ Another method is the selective modification of the external surface of the as-synthesized powder. ${ }^{98}$ The first step was the grafting of $\left(\mathrm{CH}_{3}\right)_{3} \mathrm{SiCl}$ (in isopropanol $+12 \mathrm{~N} \mathrm{HCl}$ ) on MCM-41 powder before the extraction of $\mathrm{CTMA}^{+}$. The template was then removed with a proper solvent and the porous MCM-41 was finally treated in $\mathrm{C}_{6} \mathrm{H}_{5} \mathrm{CH}_{2} \mathrm{CH}_{2} \mathrm{CH}_{2}\left(\mathrm{CH}_{3}\right)_{2} \mathrm{SiCl}$, isopropanol and $12 \mathrm{~N} \mathrm{HCl}$.

Although multiple functionalization for selective graftings is an attractive method, considering the importance of controlling the solid structure on the mesoscopic scale, one needs to be cautious in assuring the selectivity of the sites. It is because of that that we can graft a variety of silanes on the pore surface in as-synthesized mesoporous silicas, ${ }^{54,55}$ as discussed in the previous section. The simultaneous grafting and removal of surfactant of uncalcined MCM-41 was intentionally carried out to reduce the number of processes in the preparation. ${ }^{54,99}$

\section{Comparison of various modification methods designated to a similar function}

Our research group has been working on the adsorption of oxyanions such as As, $\mathrm{Cr}$, Se and $\mathrm{Mo}$ on the aminofunctionalized MCM-41, MCM-48 and SBA-1 with various kinds of aminosilanes $\left(\mathrm{H}_{2} \mathrm{NCH}_{2} \mathrm{CH}_{2} \mathrm{CH}_{2} \mathrm{Si}(\mathrm{OMe})_{3}\right.$, $\mathrm{H}_{2} \mathrm{NCH}_{2} \mathrm{CH}_{2} \mathrm{HNCH}_{2} \mathrm{CH}_{2} \mathrm{CH}_{2} \mathrm{Si}(\mathrm{OMe})_{3}$ and $\mathrm{H}_{2} \mathrm{NCH}_{2} \mathrm{CH}_{2} \mathrm{HNCH}_{2} \mathrm{CH}_{2} \mathrm{HNCH}_{2} \mathrm{CH}_{2} \mathrm{CH}_{2} \mathrm{Si}(\mathrm{OMe})_{3}$, ) and has been investigating the differences in the adsorption characteristics of the different methods of modification. ${ }^{29,38,46,83}$, 100-104 The adsorption behaviour was very sensitive to the microand meso-structure of the adsorbent. In the comparison of SBA1 (BET surface area was $1220 \mathrm{~m}^{2} \mathrm{~g}^{-1}$ and BJH pore diameter was $3.0 \mathrm{~nm}$ ) and MCM-41 (BET surface area was $1280 \mathrm{~m}^{2} \mathrm{~g}^{-1}$ and $\mathrm{BJH}$ pore diameter was $2.9 \mathrm{~nm}$ ) as grafting substrates for these silanes, we found that more silanes were grafted on SBA-1 than on MCM-41 and the apparent stoichiometric ratios of As/ $\mathrm{N}$ and $\mathrm{Cr} / \mathrm{N}$ were larger on SBA-1 than on MCM-41 when the adsorption reached saturation. The adsorption capacities were, consequently, considerably larger on amino-functionalized SBA$1 \mathrm{~s}$ than on corresponding MCM-41s. ${ }^{101}$ Although the origin of these differences is not clear, it is a lesson for designing adsorbents that two mesoporous silicas with almost the same pore size and surface area can give totally different adsorption capacities. The $\mathrm{As} / \mathrm{N}$ at adsorption saturation as a function of the loading of $\mathrm{H}_{2} \mathrm{NCH}_{2} \mathrm{CH}_{2} \mathrm{HNCH}_{2} \mathrm{CH}_{2} \mathrm{CH}_{2} \mathrm{Si}(\mathrm{OMe})_{3}$ made a good contrast between SBA-1 and MCM-41; it remained constant at $\mathrm{As} / \mathrm{N}=0.5$ for grafted SBA-1 while it decreased linearly according to the loading of silane on MCM-41 (Figure 6). Interestingly, the extrapolation of these plots to $(\mathrm{N}$ content $)=0$ $\mathrm{mmol} \mathrm{g} \mathrm{g}^{-1}$ leads to a common value of $\mathrm{As} / \mathrm{N}=0.5$, suggesting that a pair of amino groups (probably in the same organic chain) anchor an arsenate ion. The decrease found for MCM-41 may be attributed to the stack of silanes grafted near the pore windows and more uniform dispersion of the organic groups on SBA-1 than on MCM-41.

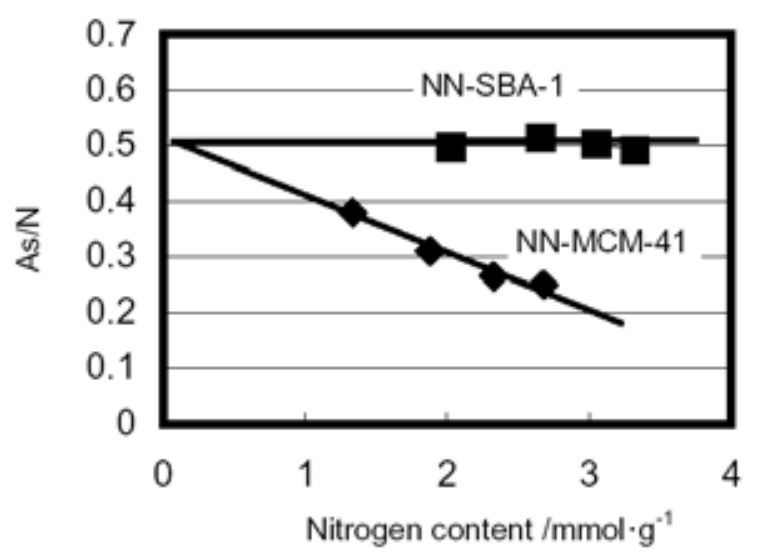

Figure $6 \mathrm{As} / \mathrm{N}$ ratio at the saturated adsorption as a function of amino group content in [1-(2-aminoethyl)-3-aminopropyl]trimethoxysilylated MCM-41 and SBA-1.

It is a simple view for the preparation strategy that the enhancement of the amount of amino groups (per g-solid) is a way to achieve high adsorption capacity. However, it is difficult to tell which method is more effective, increasing the number of amino groups in a silane molecule or increasing the surface density of silane. The former variation can be discussed from the molecular aspect while the latter variation should be considered 
in a mesoscopic view. One of the experimental results is provided by the adsorption of $\mathrm{Co}^{2+}$ shown in Figure 3. No difference was found between these two variations in the direct synthesis in which the organic groups are dispersed uniformly. A similar linearity was also found for $\mathrm{Fe}^{3+}$ adsorption on the same adsorbent. ${ }^{46}$

The removal of toxic ions for environmental remediation often needs complete adsorption because of the strict regulations created for safeguarding human health. For the adsorption strength, which is evaluated by the distribution coefficient between the solid and the solution, the larger the number of amines in the silane molecule the more stable the adsorption. This phenomenon has been revealed in arsenate adsorption on the above three kinds of aminosilane-grafted MCM-48 ${ }^{102}$ as shown in Figure 7. The gain in entropy by increasing the number of amino groups in a molecular chain reasonably explains the strong adsorption when the distance between the organic groups is large enough. In spite of the significant difference in the strength of adsorption caused by the chain structure, the central cation associated with the amino groups can be a more important factor for arsenate adsorption. ${ }^{38,}$ ${ }_{103,104}$ Figure 8 shows the same kind of $K_{\mathrm{d}}$ vs adsorption plot for $\mathrm{Fe}^{3+}, \mathrm{Co}^{2+}, \mathrm{Ni}^{2+}$ and $\mathrm{H}^{+}$anchored by $\mathrm{H}_{2} \mathrm{NCH}_{2} \mathrm{CH}_{2} \mathrm{HNCH}_{2} \mathrm{CH}_{2} \mathrm{CH}_{2} \mathrm{Si}(\mathrm{OMe})_{3}$-grafted MCM-41. (The adsorption of arsenate is an ion-exchange process and chloride leached from the solid during the process. The counter anion of these cationic sites is, therefore, $\mathrm{Cl}^{-}$.) The high distribution coefficient observed in $\mathrm{Fe}^{3+}$-cationated solid reveals a strong adsorption and a "clean removal" of arsenate. In addition, the adsorption capacity is the largest among the cations investigated. The other transition metals showed higher $K_{\mathrm{d}}$ and capacities than those of $\mathrm{H}^{+}$. The formation of an Fe-As bond was confirmed by EXAFS spectroscopy. ${ }^{38}$ Although evidence for the formation of a uniform structure was not be obtained, As : Fe : $\mathrm{N}=2.8: 1$ : 3.8 at adsorption saturation suggests a stable structure of the surface complex $\mathrm{As}_{3} \mathrm{Fe}(\mathrm{EDA}-\mathrm{Pr})_{2}$. The results from EXAFS spectroscopy support this structure.

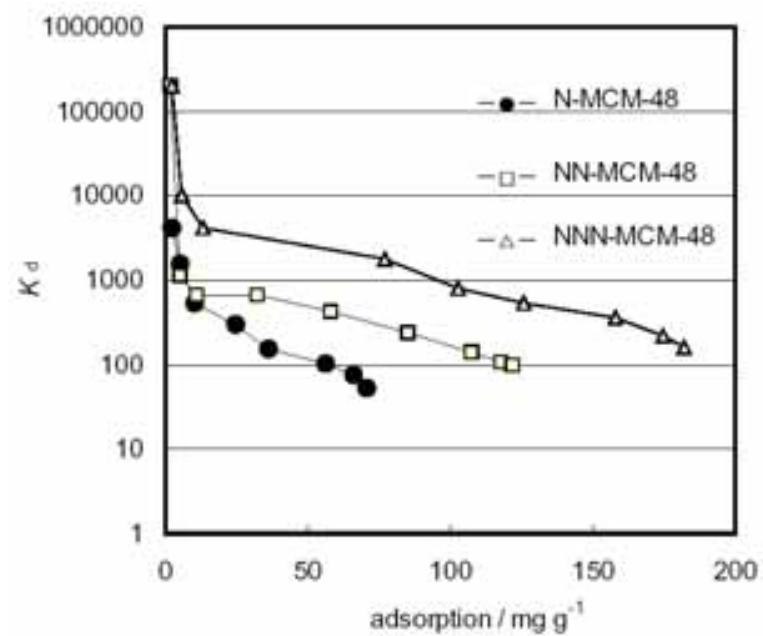

Figure 7 Distribution coefficient $\left(K_{\mathrm{d}}\right)$ and amount of arsenate adsorption on protonated amino-functionalized MCM- $48 . K_{\mathrm{d}}=\left(\right.$ As mmol $\cdot(\mathrm{g} \text {-solid })^{-}$ $\left.\left.{ }^{1}\right) /(\text { As mmol'(g-solution })^{-1}\right)$.

The characteristics of this adsorption site to be noted are that it is recyclable by treatment with hydrochloric acid as illustrated in Figure 9. It is generally difficult to desorb stable adsorbates. In this system, an excess amount of $\mathrm{HCl}$ removes arsenate and $\mathrm{Fe}^{3+}$ at the same time, which probably generates an insoluble arsenate salt, from the silica surface. After this treatment, no iron was detected, while most of the amino groups remained on the surface. The re-coordination of $\mathrm{Fe}^{3+}$ to regenerated amino groups provides a recycled adsorbent in which $90 \%$ of the adsorption capacity is restored. ${ }^{104}$ The recycling cost is considered to be low because only hydrochloric acid and iron (III) chloride are used.

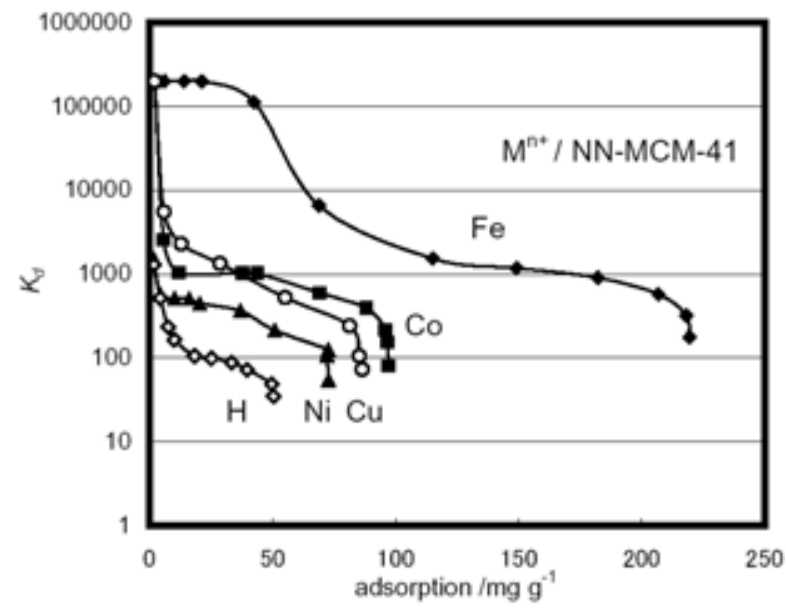

Figure 8 Distribution coefficient $\left(K_{\mathrm{d}}\right)$ and amount of arsenate adsorption on $\mathrm{Fe}^{3+}, \mathrm{Co}^{2+}, \mathrm{Cu}^{2+}, \mathrm{Ni}^{2+}$ and $\mathrm{H}^{+}$cationated $\mathbf{H}_{2} \mathrm{NCH}_{2} \mathrm{CH}_{2} \mathbf{H N C H}_{2} \mathrm{CH}_{2} \mathrm{CH}_{2}$-functionalized MCM-41. $K_{\mathrm{d}}=2 \times 10^{5}$ was the detection limit. We can define the adsorption capacities at the point where $K_{\mathrm{d}}$ drops vertically. $K_{\mathrm{d}}=\left(\right.$ As $\left.\mathrm{mmol} \cdot(\mathrm{g} \text {-solid })^{-1}\right) /($ As $\mathrm{mmol} \cdot(\mathrm{g}-$ solution) $)^{-1}$ ).

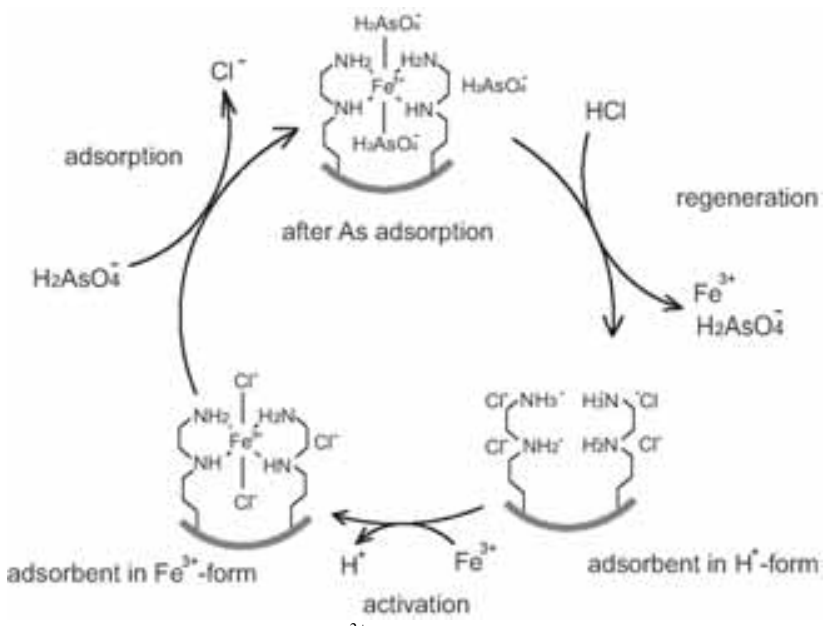

Figure 9 Recycling of $\mathrm{Fe}^{3+}$-diamino-MCM-41 after adsorption of arsenate.

In-advance silane preparation and post on-surface synthesis on MCM-41 were compared for 2,2,6,6-tetramethyl-1piperidinyloxy (TEMPO) modified mesoporous silica and the catalytic oxidation of primary alcohol to aldehyde. ${ }^{105}$ As shown in Scheme 5, the amount of TEMPO loaded on the mesoporous silica was larger by in-advance preparation than by post onsurface synthesis. The conversion of the 3-aminopropyl group into the designated organic group was as low as $27 \%$. The conversion of 1,4-pentadiol into $\gamma$ - valerolactone with $\mathrm{m}$ chloroperbenzoic acid as a bulk oxidant was $50 \%\left(\mathrm{TON}=30 \mathrm{~h}^{-}\right.$ $\left.{ }^{1}\right)$ on catalyst I while it reached $99 \%\left(\mathrm{TON}=60 \mathrm{~h}^{-1}\right)$ on catalyst II under the same reaction conditions. The authors of this study attributed the large reaction rate to the promoting effect of protonated residual amino group in the chain of catalyst II.

Stein et al incorporated meso-tetrakis(5trimethylammoniopentyl)porphyrin (TMAP) into MCM-41 by direct co-condensation and by grafting at the "assynthesized" stage (namely, by ion-exchange). ${ }^{106}$ The amount of incorporated porphyrin in the latter solid was about five times larger than in the former. TMAP was dimerized or formed larger agglomerates in the ion-exchanged MCM-41, while it remained isolated in the co-condensation sample. After acid extraction of the surfactant, the encapsulated porphyrin $\mathrm{TMAPH}_{2}{ }^{+}$was 
obtained, which further trapped metal cations. The catalytic activity of $\mathrm{Cu}^{2+}$-TMAP was examined for the oxidative bleaching reaction of $\beta$-naphthol violet. $\mathrm{Cu}^{2+}$-TMAP was degraded in the ion-exchange sample while it showed a larger catalytic activity for a long period in the co-condensation sample. The authors suggested that the isolation of TMAP molecules prevented their mutual oxidation.

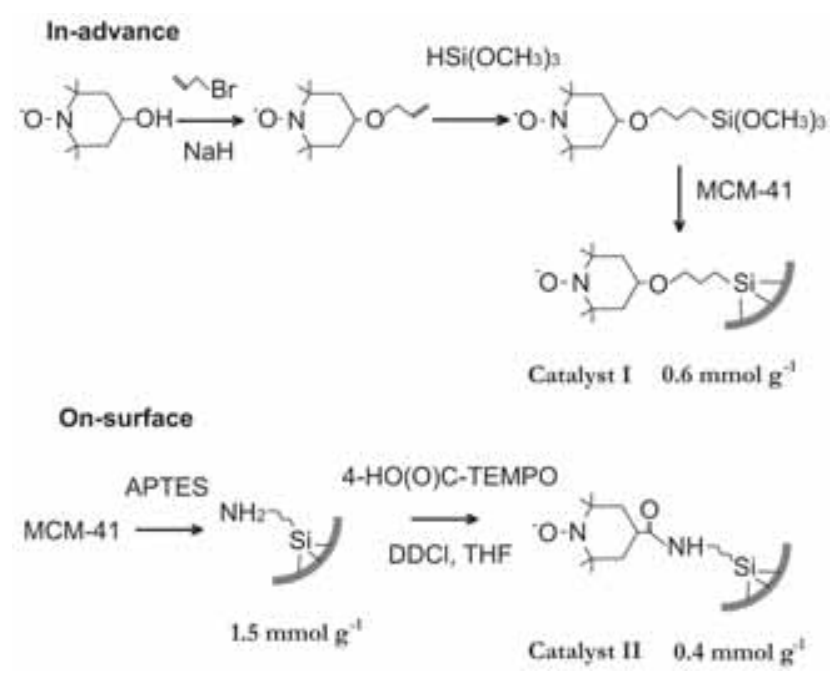

Scheme 5 Synthesis of TEMPO-MCM-41s via two routes. The amount of functional groups is shown.

Several other comparative studies on the different preparation procedures are found in the literature. ${ }^{53,107-110}$ The number of works is on the functions of materials prepared by the grafting / co-condensation / coating methods, and in-advance silane synthesis / post on-surface synthesis is still limited.

\section{Future and Outlook}

Periodic mesoporous oraganosilicas ${ }^{111}$ synthesized by employing bridged silsesquioxanes as silica sources are an emerging family of porous materials. For modification with organic groups, the materials of this category are attractive as they have an arrangement of different kinds of chemical bonds connected alternatively, which has opened up a new dimension of periodicity. The reagents can react on $\mathrm{Si}-\mathrm{OH}$ bonds as well as bridging (or bridged) organic groups such as $-\mathrm{C}=\mathrm{C}$ - and $-\mathrm{C}_{6} \mathrm{H}_{4}-$. The chemical properties of these surface sites are sufficiently different to consider them suitable for reactions for modification. ${ }^{112}$ Although modification has been carried out mainly by direct co-condensation, ${ }^{113-115}$ the combination with the preparation methods described above could further extend the variation of structure and function in these porous materials.

The other possibility in the near future is a fusion of the modification of mesoporous silica with molecular imprinting techniques. ${ }^{116,117}$ There have already been attempts to control the configuration of two silanes during grafting 118 and direct synthesis ${ }^{51}$ by coordinating a transition metal cation, which is to be used in trapping the same cation. However, molecular imprinting is applicable to various organic compounds for a guest molecule and further development is expected.

\section{Acknowledgements}

The author gives thanks to Prof. T. Tatsumi for his collaboration and support. This project has been carried out with young coworkers, Dr. T. Yokoi, Mr. H. Horie and Ms. E. Koiso, for whom I specially thank. I am also grateful to The Ministry of Education, Culture, Sports, Science and Technology, Japan
Society for the Promotion of Science, the Asahi Glass Foundation, Tokuyama Science Foundation, The Japan Securities Scholarship Foundation, Japan Science and Technology Agency and Yokohama Academic Foundation for financial support.

\section{References}

1 T. Yanagisawa, T. Shimizu, K. Kuroda and C. Kato, Bull. Chem. Soc. Jpn., 1990, 63, 988.

2 C. T. Kresge, M. E. Leonowicz, W. J. Roth, J. C. Vartuli, and J. S. Beck, Nature 1992, 359, 710.

3 T. Ishikawa, M. Matsuda, A. Yasukawa, K. Kandori, S. Inagaki, T. Fukushima and S. Kondo, J. Chem. Soc., Faraday Trans., 1996, 92, 1985.

4 C. P. Jaroniec, M. Kruk, J. Jaroniec and A. Sayari, J. Phys. Chem. B, 1998, 102, 5503.

5 X. S. Zhao and G. Q. Lu, J. Phys. Chem. B, 1998, 102, 1556.

6 (a) J. Liu, X. Feng, G. E. Fryxell, L. Q. Wang, A. Y. Kim and M. Gong, Adv. Mater., 1998, 10, 161. (b) G. E. Fryxell and J. Liu, Adsorption on Silica Surfaces, edited by Eugene Papirer, Marcel Dekker, pp.665, 2000.

7 A. Sayari and S. Hamoudi, Chem. Mater. 2001, 13, 3151.

8 (a) J. H. Clark and D. J. Macquarrie, Chem. Commun., 1998, 853. (b) J. H. Clark, D. J. Macquarrie and K. Wilson, Stud. Surf. Sci. Catal., 2000, 129, 251.

9 K. Moller and T. Bein, Chem. Mater., 1998, 10, 2950.

10 A. Stein, B. J. Melde and R. C. Schroden, Adv. Mater., 2000, 12, 1403.

11 R. Anwander, Chem. Mater., 2001, 13, 4419.

12 G. Kickelbick, Angew. Chem. Int. Ed., 2004, 43, 3102.

13 C. Nozaki, C. G. Lugmair, A. T. Bell and T. D. Tilley, J. Am. Chem. Soc., 2002, 124, 13194.

14 C. J. Miller and D. O'Hare, Chem. Commun., 2004, 1710.

15 R. Anwander, H. W. Görlitzer, G. Gerstberger, C. Palm, O. Runte and M. Spielgler, J. Chem. Soc., Dalton Trans., 1999, 3611.

16 I. C. Chisem, J. Rafelt, M. T. Shieh, J. Chisem, J. H. Clark, R. Jachuck, D. Macquarrie, C. Ramshaw and K. Scott, Chem. Commun., 1998, 1949.

17 S. Xiang, Y. Zhang, Q. Xin and C. Li, Angew. Chem., Int. Ed., 2002, 41, 821 .

18 S. Dai, M. C. Burleigh, Y. Shin, C. C. Morrow, C. E. Barnes and Z. Xue, Angew. Chem., Int. Ed., 1999, 38, 1235.

19 M. Álvaro, M. Benitex, D. Das, B. Ferrer and H. García, Chem. Mater., 2004, 16, 2222.

20 W. M. Van Rhijin, D. E. DeVos, B. F. Sels, W. D. Bossaert and P. A. Jacobs, Chem. Commun., 1998, 317.

21 E. Cano-Serrano, J. M. Campos-Marin and J. L. G. Fierro, Chem. Commun., 2003, 246.

22 K. Wilson and J. H. Clark, Pure Appl. Chem., 2000, 72, 1313.

23 R. J. P. Corriu, A. Mehdi, C. Reyé and C. Thieuleux, Chem. Mater., 2004, 16, 159

24 P. Sutra and D. Brunel, Chem. Commun., 1996, 2485.

25 Y. V. S. Rao, D. E. De Vos, T. Bein and P. A. Jacobs, Chem. Commun., 1997, 355

26 (a) A. Derrien and G. Renard, D. Brunel, Stud. Surf. Sci. Catal., 1998, 117, 445. (b) A. C. Blanc, D. J. Macquarrie, S. Valle, G. Renard, C. R. Quinn and D. Brunel, Green Chem., 2000, 2, 283.

27 X. J. Feng, X. B. Lu and R. He, Appl. Catal., 2004, $272,347$.

28 J. Ding, C. J. Hudalla, J. T. Cook, D. P. Walsh, C. E. Boissel, P. C. Iraneta and J. E. O'Gara, Microporous Mesoporous Mater., 2004, 16, 670 .

29 H. Yoshitake, E. Koiso, T. Tatsumi, H. Horie and H. Yoshimura, Chem. Lett., 2004, 872.

30 D. J. Macquarrie and S. E. Fairfield, J. Mater. Chem., 1997, 7, 2201.

31 J. H. Clark, S. J. Tavener and S. J. Barlow, Chem. Commun., 196, 2429.

32 J. Ding, C. J. Hudalla, J. T. Cook, D. P. Walsh, C. E. Boissel, P. C. Iraneta and J. E. O'Gara, Chem. Mater., 2004, 16, 670-681.

33 C. Tourné-Péteilh, D. Brunel, S. Bégu, B. Chiche, F. Fajula, D. A. Lerner and J. M. Devoisselle, New J. Chem., 2003, 27, 1415.

34 J. F. Diaz and K. J. Balkus Jr., Chem. Mater., 1997, 9, 61.

35 D. J. Park, S. S. Park and S. J. Choe, Bull. Korean Chem. Soc., 1999, 20, 291.

36 G. E. Fryxell, J. Liu, T. A. Hauser, Z. Nie, K. F. Ferris, S. Mattigod, M. Gong and R. T. Hallen, Chem. Mater., 1999, 11, 2148. 
37 J. Evans, A. B. Zaki, M. Y. El-Sheikh and S. A. El-Safty, J. Phys. Chem. B, 2000, 104, 10271.

38 H. Yoshitake, T. Yokoi, T. Tatsumi, Chem. Mater., 2003, 15, 1713.

39 Y. Gao, J. C. Hu, P. Yang, W. L. Dai and K. N. Fan, Chem. Commun., 2003, 908.

40 C. J. Liu, S. G. Li, W. Q. Pang and C. M. Che, Chem. Commun. 1997, 65.

41 S. Gago, Y. Zhang, A. M. Santos, K. Köhler, F. E. Kühn, J. A. Fernandes, M. Pillinger, A. A. Valente, T. M. Santos, P. J. A. Ribeiro-Claro and I. S. Gonçalves, Microporous Mesoporous Mater., 2004, 76, 131.

42 T. Joseph, S. S. Deshpande, S. B. Halligudi, A. Vinu, S. Ernst and M. Hartmann, J. Mol. Catal. A, 2003, 206, 13.

43 I. Nagl, M. Widenmeyer, S. Grasser, K. Köhler amd R. Anwander, J. Am. Chem. Soc., 2000, 122, 1544.

44 R. Anwander, I. Nagl, C. Zapilko and M. Widenmeyer, Tetrahedron, 2003, 59, 10567.

45 S.D. Kelly, K. M. Kemner, G. E. Fryxell, J. Liu, S. V. Mattigod and K. F. Ferris, J. Phys. Chem. B, 2001, 105, 6337.

46 T. Yokoi, H. Yoshitake and T. Tatsumi, J. Mater. Chem., 2004, 14, 951.

47 A. Walcarius, M. Etienne and J. Bessière, Chem. Mater., 2002, 14, 2757.

48 A. Walcarius, M. Etienne and J. Bessière, Chem. Mater., 2003, 15, 2161.

49 A. Bibby and L. Mercier, Chem. Mater., 2002, 14, 1591.

50 S. Dai, M. C. Burleigh, Y. Shin, C. C. Morrow, C. E. Barnes and Ziling Xue, Angew, Chem. Int. Ed., 1999, 38, 1235.

51 H. Zhu, D. J. Jones, J. Zajac, R. Dutartre, M. Rhomari and J. Rozière, Chem. Mater., 2002, 14, 4886.

52 M. W. McKittrick and C. W. Jones, Chem. Mater., 2003, 15, 1132.

53 M. H. Lim and A. Stein, Chem. Mater. 1999, 11, 3285.

54 V. Antochshuk and M. Jaroniec, Chem. Mater., 2000, 12, 2496.

55 A. B. Bourlinos, T. Karakostas and D. Petridis, J. Phys. Chem. B, 2003, 107, 920 .

56 A. Badiei and L. Bonneviot, Inorg. Chem., 1998, 37, 4142.

57 F. Béland, A. Badiei, M. Rönning, D. Nicholson and L. Bonneviot, Phys. Chem. Chem. Phys., 1999, 1, 605.

58 S. Abry, B. Albela and L. Bonneviot, C. R. Chem., 2005, 8, 741.

59 X. Feng, G. E. Fryxell, L. Q. Wang, A. Y. Kim, J. Liu and K. M. Kemner, Science, 1997, 276, 923.

60 S. L. Burkett, S. D. Sims and S. Mann, Chem. Commun., 1996, 1367. 61 D. J. Macquarrie, Chem. Commun., 1996, 1961.

62 Q. Huo, D. I. Margolese, G. D. Stucky, Chem. Mater., 1996, 8, 1147.

63 C. E. Fowler, S. L. Burkett and S. Mann, Chem. Commun., 1997, 1769.

64 M. H. Lim, C. F. Blanford and A. Stein, Chem. Mater., 1998, 10, 467.

65 (a) C. E. Fowler, B. Lebeau and S. Mann, Chem. Commun., 1998, 1825. (b) S. R. Hall, C. E. Fowler, B. Lebeau and S. Mann, Chem. Commun., 1999, 201.

66 D. J. Macquarrie, D. B. Jackson, J. E. G. Mdoe and J. H. Clark, New J. Chem., 1999, 23, 539.

67 W. M. van Rhijn, D. E. De Vos, W. Bossaert, J. Bullen, B. Wouters, P. J. Grobet and P. A. Jacobs, Stud. Surf. Sci. Catal., 1998, 117, 183.

68 V. Goletto, V. Dagry and F. Babonneau, Mat. Res. Soc. Symp. Proc., 1999, 576, 229.

69 L. Mercier and T. J. Pinnavaia, Chem. Mater., 2000, 12, 188.

70 Y. Mori and T. J. Pinnavaia, Chem. Mater., 2001, 13, 2173.

71 R. Richer and L. Mercier, Chem. Commun., 1998, 1775.

72 J. Brown, R. Richer and L. Mercier, Microporous Mesoporous Mater., 2000, 37, 41.

73 L. Beaudet, K. Z. Hossain and L. Mercier, Chem. Mater., 2003, 15, 327.

74 R. J. P. Corriu, A. Mehdi, C. Reyé and C. Thieuleux, Chem. Commun., 2004, 1440.

75 A. S. M. Chong and X. S. Zhao, J. Phys. Chem. B, 2003, 107, 12650.

76 C. Yang, Y. Wang, B. Zibrowius and F. Schüth, Phys. Chem. Chem. Phys., 2004, 6, 2461.

77 X. Wang, K. S. K. Lin, Jerry, C. C. Chan and S. Cheng, Chem. Commun., 2004, 2762.

78 J. A. Melero, G. D. Stucky, R. van Grieken and G. Morales, J. Mater. Chem., 2002, 12, 1664.

79 A. S. M. Chong, X. S. Zhao, A. T. Kustedjo and S. Z. Qiao, Microporous Mesoporous Mater., 2004, 72, 33.

80 M. H. Lim, C. F. Blanford and A. Stein, J. Am. Chem. Soc., 1997, 119, 4090 .
81 M. H. Lim and A. Stein, Mater. Res. Soc. Symp. Proc., 1998, 519, 89.

82 K. Moller, T. Bein and R. X. Fischer, Chem. Mater., 1999, 11, 665.

83 (a)T. Yokoi, H. Yoshitake and T. Tatsumi, Chem. Mater., 2003, 15, 4536. (b) T. Yokoi, H. Yoshitake and T. Tatsumi, Stud. Surf. Sci. Catal., 2004, 154A, 519.

84 Q. Zhang, K. Ariga, A. Okabe and T. Aida, J. Am. Chem. Soc., 2004, 126, 988

85 S. H. Lim, H. Yoshitake and T. Tatsumi, Stud. Surf. Sci. Catal., 2003, 146, 129

86 F. Cagnol, D. Grosso and C. Sanchez, Chem. Commun., 2004, 1742.

87 Y. Okahara, K. Ariga, H. Nakahara and K. Fukuda, J. Chem. Soc., Chem. Commun., 1986, 1069.

88 K. Ariga and Y. Okahata, J. Am. Chem. Soc., 1989, 111, 5618.

89 K. Katagiri, K. Ariga and J. Kikuchi, Chem. Lett. 1999, 661.

90 J. J. E. Moreau, L. Vellutini, M. W. C. Man, C. Bied, J. L. Bantignies, P. Dieudonne and J. L. O. Sauvajol, J. Am. Chem. Soc., 2001, 123, 7957.

91 K. Katagiri, R. Hamazaki, K. Ariga and J. Kikuchi, J. Am. Chem. Soc., 2002, 124, 7892 .

92 A. Shimojima and K. Kuroda, Langmuir, 2002, 18, 1144.

93 Q. Huo, D. E. Margolese and G. D. Stucky, Chem. Mater., 1996, 8, 1147.

94 E. Ruiz-Hitzky, S. Letaïef and V. Prevot, Adv. Mater., 2002, 14, 439.

95 S. Che, Z. Liu, T. Ohsuna, K. Sakamoto, O. Terasaki and T. Tatsumi, Nature, 2004, 429, 281.

96 D. S. Shephard, W. Zhou, T. Maschmeyer, J. M. Matters, C. L. Roper, S. Parsons, B. F. G. Johnson and M. J. Duer, Angew. Chem. Int. Ed. 1998, 37, 2719.

97 B. F. Johnson, S. T. Raynor, D. S. Shepard, T. Maschmeyer, J. M. Thomas, G. Sankar, S. Bromley, R. Oldroyd, L. Gladden and M. D. Mantle, Chem. Commun., 1999, 1167.

98 F. de Juan and E. Ruiz-Hitzky, Adv. Mater. 2000, 12, 430.

99 V. Antochshuk and M. Jaroniec, Chem. Commun., 1999, 2373.

100 H. Yoshitake, T. Yokoi and T. Tatsumi, Chem. Lett., 2002, 586

101 H. Yoshitake, T. Yokoi and T. Tatsumi, Chem. Mater. 2002, 14, 4603.

102 H. Yoshitake, T. Yokoi and T. Tatsumi, Bull. Chem. Soc. Jpn., 2003, 76, 847.

103 H. Yoshitake, T. Yokoi and T. Tatsumi, Bull. Chem. Soc. Jpn., 2003, 76, 2225.

104 T. Yokoi, T. Tatsumi and H. Yoshitake, J. Colloid. Interf. Sci., 2004, 274, 451.

105 D. Brunel, F. Fajula, J. B. Nagy, B. Deroide, M. J. Verhoef, L. Veum, J. A. Peters and H. van Bekkum, Appl. Catal. A, 2001, 213, 73.

106 B. T. Holland, C. Walkup and A. Stein, J. Phys. Chem. B, 1998, 102, 4301 .

107 R. Huq, L. Mercier, P. J. Kooyman, Chem. Mater., 2001, 13, 4512.

108 (a) R. J. P. Corriu, A. Mehdi, C. Reyé and C. Thieuleux, Chem. Commun., 2002, 1382. (b) R. J. P. Corriu, A. Mehdi, C. Reyé and C. Thieuleux, New J. Chem., 2003, 27, 905, (c) R. J. P. Corriu, A. Mehdi, C. Reyé and C. Thieuleux, Chem. Commun., 2003, 1564.

109 T. Pruß, D. J. Macquarrie and J. H. Clark, J. Mol. Catal. A, 2004, 211, 209.

110 T. Martin, A. Galarneau, D. Brunel, V. Izard, V. Hulea, A. C. Blanc, S. Abramson, F. Di Renzo and F. Fajula, Stud. Surf. Sci. Catal., 2001, 135, 4621 .

111 For recent reviews, see (a) S. Inagaki, Stud. Surf. Sci. Catal. 2004, 148 , 109. (b) G. Kickelbick, Angew. Chem. Int. Ed., 2004, 43, 3102. (c)M. Antonietti and G. A. Ozin, Chemistry - A European Journal, 2004, 10, 28.

112 Q. Yang, M. P. Kapoor and S. Inagaki, J. Am. Chem. Soc., 2002, 124, 9694.

113 S. Hamoudi, S. Royer, S. Kaliaguine, Microporous Mesoporous Mater., 2004, 71, 17.

114 M. C. Burleigh, M. A. Markowitz, M. S. Spector and B. P. Gaber, J. Phys. Chem. B, 2001, 105, 9935.

115 T. Asefa, M. Kruk, M .J. MacLachlan, N. Coombs, H. Grondey, M. Jaroniec and G. A. Ozin, J. Am. Chem. Soc., 2001, 123, 8520.

116 (a) A. Katz and M. E. Davis, Nature, 2000, 403,286. (b) J. D. Bass and A. Katz, Chem. Mater., 2003, 15, 2757. (c) J. D. Bass, S. L. Anderson and A. Katz, Angew. Chem. Int. Ed., 2003, 42, 5219.

117 (a) A. Suzuki, M. Tada and Y. Iwasawa, J. Mol. Catal. A, 2002, 182, 125. (b) M. Tada, T. Sasaki and Y. Iwasawa, Phys. Chem. Chem. Phys., 2002, 4, 4561.(c) M. Tada and Y. Iwasawa, J. Mol. Catal. A, 2003, 204, 27. 
118 S. Dai, M. C. Burleigh, Y. Shin, C. C. Morrow, C. E. Barnes and Z. Xue, Angew. Chem. Int. Ed., 1999, 38, 1235. 